\title{
Study on Nurses Knowledge Corresponding Pain Management
}

\author{
Abdulkareem Salman Khudhair ${ }^{*}$, Wasfi Dhahir Abid $\mathrm{Ali}^{2}$, Hind Kareem Kataa ${ }^{3}$
}

1Department of Fundamentals of Nursing, College of Nursing -University of Basra, Iraq Master in Adult Nursing
${ }^{2}$ Department of Basic Sciences, College of Nursing -University of Basra, Iraq -Ph.D in Physiology
${ }^{3}$ Department of Basic Sciences, College of Nursing -University of Basra Iraq Master in Computer Science, Student in Nursing College

DOI: $10.36347 /$ sjahss.2020.v08i04.007

| Received: 26.03.2020 | Accepted: 02.04.2020 | Published: 28.04.2020

*Corresponding author: Abdulkareem Salman Khudhair

Abstract

Original Research Article

Nurses play an important role in pain management; pain may adversely affect quality of life, and indeed, the development of illness itself. Although the means to control pain is available for the majority of cases, the prevalence of pain in health institutions and the community is still high. This project conducted from November 2018 till April 2019 in Basra teaching hospital and aims to assess nurse's knowledge regarding pain management. A hundred five nurses were randomly chosen to identify nurse's knowledge regarding Pain management. The study instrument was comprised of questions taken by written include socio-demographic characteristics and nurse's knowledge regarding pain management. The study revealed that the percentage of female (63.67\%) is higher than male (36.23). Field of work distribution showed that the percentage of pediatric (33.34\%) and surgery (26.66) more than care unit (20.95) and emergency $(19.05 \%)$. According to educational level secondary nursing school were the higher percentage (45.78\%) other include Medical institute Diplomat (34.18\%) Bachelors (20.04). In case of questionnaire knowledge the percentage of correct answers (52.02) while the incorrect were (47.98) were nearly equals, while the mean of score 1.60). The conclusion that the female nurses were higher than male in hospitals, Secondary school nurse were the permeant, most nurses have 1-5 year of experience. Finally the Knowledge's about pain management were not adequate among nurses.

Keywords: Pain, management, Knowledge.

Copyright @ 2020: This is an open-access article distributed under the terms of the Creative Commons Attribution license which permits unrestricted use, distribution, and reproduction in any medium for non-commercial use (NonCommercial, or CC-BY-NC) provided the original author and source are credited.

\section{INTRODUCTION}

Although the means to control pain is available for the majority of cases, the prevalence of pain in health institutions and the community is still high [1].

Therefore, in many cases, pain is both unnecessary and avoidable. The reasons for this may lie in the scant interest and attention of health professionals regarding pain and the lack of familiarity with the drugs and methods that are usually effective in controlling pain. In an attempt to assess this assumption, there have been numerous studies dealing with the trainings of health care professionals and their attitudes toward patients in pain. To varying degrees, professionals have been found to lack knowledge and the correct attitude toward pain [2]. Pain is widely prevalent regardless of the setting in which patients are being managed and deemed to be one of the most reasons for patients to seek medical care[3]. Likewise more than 25 million people experience acute pain as a result of injury or surgery. Unrelieved or undertreated pain can negatively affect an array of person's quality of life, including increasing functional impairment and disability, psychological distress (anxiety, depression), and sleep deprivation [4]. Scientific facts that accompany the uses and misuses of opioid medication continue to pose a perpetual challenge to appropriately handle chronic pain and thus left chronic pain to be a major medical and social issue [5].

\section{METHODOLOGY}

This study was across- sectional involving (105) nurses regarding in Basra teaching hospital to achieve the aim of the study. Questionnaire was designed and, to identify nurse's knowledge regarding pain management. The study started from Nov. 2018 till April 2019.

A hundred five nurses were chose to identify nurse's knowledge regarding Pain management. The study instrument was comprised of questions taken by written. Before Introduce this items distributed for (3) teachers of college. These items distributed to care givers of Basra hospital in Basra city (105) and it 
divided in to Main parts, the first part was to identify the socio-demographic characteristics and Second part was nurse's knowledge regarding pain management. Statistical data analysis includes Percentage, Frequency, as well as used of mean of score for data analysis and significant investigation.

\section{RESULTS AND DISCUSSION}

In recent years, there has been a growing awareness among health care professionals and the public in general, concerning the importance of guaranteeing effective pain management for patients [5]. The data of the recent project in table (1) showed that the percentage of female (63.67) was higher than male (36.23) and that may be due to the education minister and higher education minister and scientific researches accepted female more than male in secondary nursing school and college of nursing.

On other hand the study revealed that the percentage of nurses in pediatric and surgery units $(33.34 \%, 26.66 \%)$ respectively, while in care unit $(20.95 \%)$ and emergency $19.05 \%)$ were less, that relegated to the need of high qualified nurses in surgery and pediatric. About the nurses educational level, secondary schools nurses were established for long periods before medical institute and nursing college nurses whom had secondary education are more dominants $(45.71 \%)$, while diplomate level 34.28\%, Bachelor $19.04 \%$ respectively. Year of experience for nurses had (1-5) year are the higher in percentage compare with the other this may be due to the acceptation of more nurses to work in government hospitals in the past five year.

Table-1: Demographic information percentage for nurses

\begin{tabular}{|l|l|l|}
\hline \multirow{2}{*}{ Gender } & & ercentage \\
\hline \multirow{4}{*}{ Educational level } & female & 63.67 \\
\cline { 2 - 3 } & male & 36.23 \\
\hline \multirow{4}{*}{ years of experience } & Secondary & 45.71 \\
\cline { 2 - 3 } & Diplomate & 34.28 \\
\cline { 2 - 3 } & Bachelor & 19.04 \\
\hline \multirow{5}{*}{ Field of work } & $1-5$ & 38.09 \\
\cline { 2 - 3 } & $6-10$ & 25.71 \\
\cline { 2 - 3 } & $11-15$ & 14.28 \\
\cline { 2 - 3 } & $16-20$ & 11.42 \\
\cline { 2 - 3 } & 20 and over & 10.47 \\
\hline & Emergency & 19.05 \\
\cline { 2 - 3 } & Surgery & 26.66 \\
\cline { 2 - 3 } & pediatric & 33.34 \\
\cline { 2 - 3 } & Care unit & 20.95 \\
\hline
\end{tabular}

\begin{tabular}{|c|c|c|c|}
\hline No & Question & MS & $\mathbf{S}$ \\
\hline 1 & Giving narcotics on a regular schedule is preferred over "p.r.n." schedule for continuous pain & 1.72 & $\mathrm{~S}$ \\
\hline 2 & A patient should experience discomfort prior to giving the next dose of pain meds & 1.53 & $\mathrm{~S}$ \\
\hline 3 & The preferred rule of administration of narcotic pain relievers to patients with pain is intramuscular & 1.42 & NS \\
\hline 4 & $\begin{array}{l}\text { When a patient requests increasing amounts of analgesics to control pain, this usually indicates that the } \\
\text { patient is psychologically dependent }\end{array}$ & 1.59 & $\mathrm{~S}$ \\
\hline 5 & Patients receiving narcotics on a "p.r.n."” basis may be likely to develop clock-watching behaviors & 1.67 & $\mathrm{~S}$ \\
\hline 6 & $\begin{array}{l}\text { When a patient in pain is receiving analgesic medication on a "p.r.n." basis, it is appropriate for the patient } \\
\text { to request pain meds before the pain returns }\end{array}$ & 1.37 & NS \\
\hline 7 & Staff can always pick up cues from children that indicate that they are in pain. & 1.72 & $\mathrm{~S}$ \\
\hline 8 & Children cry all the time, therefore, diversional activities are indicated rather than actual pain meds & 1.68 & S \\
\hline 9 & $\begin{array}{l}\text { The most suitable dose of morphine for a patient in pain is a dose that best controls the symptoms; there is no } \\
\text { maximum dose (i.e., a level that must not be exceeded) for morphine }\end{array}$ & 1.58 & S \\
\hline 10 & It may often be useful to give a placebo to a patient in pain to assess if he is genuinely in pain & 1.54 & S \\
\hline 11 & $\begin{array}{l}\text { For effective treatment of cancer pain it is necessary to continuously assess the pain and the efficacy of the } \\
\text { therapy }\end{array}$ & 1.79 & S \\
\hline 12 & It is a patient's right to expect total pain relief as a consequence of treatment & 1.61 & $\mathrm{~S}$ \\
\hline 13 & Lack of pain expression does not mean lack of pain & 1.62 & S \\
\hline 14 & Distraction, for example, by the use of music or relaxation, can decrease the perception of pain & 1.62 & S \\
\hline 15 & Patients having severe chronic pain often need higher dosages of pain meds than patients with acute pain & 1.57 & $\mathrm{~S}$ \\
\hline 16 & Patients having severe chronic pain often need higher dosages of pain meds than patients with acute pain & 1.57 & S \\
\hline 17 & Increasing analgesic requirements are signs that the patient is becoming addicted to the $\mathrm{n}$ narcotic & 1.67 & $\mathrm{~S}$ \\
\hline 18 & $\begin{array}{l}\text { If a patient (and/or family member) reports that a narcotic is causing euphoria, s/he should be given a lower } \\
\text { dose of the analgesic }\end{array}$ & 1.62 & S \\
\hline & Total & 1.60 & S \\
\hline
\end{tabular}

Table (1) the mean of score of the questions answers regarding pain management

$\mathrm{MS}=$ mean of score $\mathrm{S}=$ Significant NS =non-significant 
The answers of questionnaire regarding pain management by the nurses in the selected hospitals showed in table(2) that the percentage correct answers (52.01) while the incorrect were(47.98) were nearly equals that give idea that the nurses have no adequate information about pain managements. The mean score for answers were significant except question (3 and 6) were no significant, which responsible for analgesic medication administration role.

The currents study provides us with valuable information on the level of nurses' knowledge regarding pain management in Basrah teaching hospital in different fields of work, with agreement with our results in care units of Palestine results demonstrated that Palestinian nurses in high acuity care units have inadequate knowledge and negative attitudes toward pain management [6]. A Turkish study of "Knowledge and Attitudes of Nurses regarding Pain Management" had an average of correct answers $=15.86(\mathrm{SD}=$ 7.33)[7].

Al-Qadire and Al Khalaileh who reported that the average of the correct answers to the 40 questions answered in the questionnaire was 19.3 (SD 4.7)[8].

The total mean score of the present study was 1.60 (significant,) while the mean score for knowledge was $45 \%$, which indicates inadequate knowledge regarding pain management [6].

Saudi nurses showed a lower level of pain knowledge compared with nurses from other regional and worldwide nurses. It is recommended to considered pain management in continuous education and nursing undergraduate curricula [9].

Several studies have described the barriers to delivery of an effective pain management Limited knowledge and negative attitude of nurses toward pain management were reported as major obstacles in the implementation of an effective pain management [10, 11]. As general reasons behind nurses' insufficiency of knowledge and poor attitudes toward pain in might be due to their educational level and inadequate lecture hours on courses pertaining to pain management in the nursing curriculum.

\section{CONCLUSION}

The currents study provides us with valuable information on the level of nurses' knowledge regarding pain management the correct answers and incorrect were nearly equals that give idea that the nurses have no adequate information about pain managements.

\section{REFERENCES}

1. Visentin M, Zanolin E, Trentin L, Sartori S, de Marco R. Prevalence and treatment of pain in adults admitted to Italian hospitals. European Journal of Pain. 2005 Feb;9(1):61-7.

2. Ponte CD, Johnson-Tribino J. Attitudes and knowledge about pain: an assessment of West Virginia family practitioners. Fam 2005.Med. 2005; 37(7): 477e480.

3. Virginia W. Attitudes and knowledge about pain: an assessment of West Virginia family physicians. Fam Med. 2005;37(7):477-80.

4. Simon LS. Relieving pain in America: A blueprint for transforming prevention, care, education, and research. Journal of pain \& palliative care pharmacotherapy. 2012 Jun 22;26(2):197-8.

5. Klipa D, Russeau JC. Pain and Its Management. Applied Therapeutics: Clinical use of drugs. $\left(9^{\text {th }}\right.$ edn), Lippincott Williams \& Wilkins, Philadelphia; 2009.

6. Coleman EA, Goodwin JA, Coon SK, Richards K, Enderlin C, Kennedy R, Stewart MC, McNatt MP, Lockhart MK, Anaissie EJ, Barlogie B. Fatigue, sleep, pain, mood and performance status in patients with multiple myeloma. Cancer nursing. 2011 May;34(3):219.

7. Basma Salameh, Nurses' knowledge regarding pain management in high acuity care units: A case study of Palestine, Int J Health Sci (Qassim). 2018 MayJun; 12(3): 51-57.

8. Yava A, Çicek H, Tosun N, Özcan C, Yildiz D, Dizer B. Knowledge and Attitudes of Nurses about Pain Management in Turkey. International Journal of Caring Sciences. 2013 Sep 1;6(3).

9. Khalaileh MA, Qadire MA. Pain management in Jordan: nursing students' knowledge and attitude. British Journal of Nursing. 2013 Dec 11;22(21):1234-40.

10. Samarkandi OA. Knowledge and attitudes of nurses toward pain management. Saudi journal of anaesthesia. 2018 Apr;12(2):220.

11. Bartoszczyk DA, Gilbertson-White S. Interventions for nurse-related barriers in cancer pain management. Oncol Nurs Forum. 2015;42:634-41.

12. Kwon JH. Overcoming barriers in cancer pain management. J Clin Oncol. 2014;32:1727-33. 